\title{
O LEGADO DE FLORENCE NIGHTINGALE: UMA VIAGEM NO TEMPO
}

\author{
Roberta Costaํ, Maria Itayra Padilha², Lúcia Nazareth Amante ${ }^{3}$, Eliani Costa4, Lisnéia Fabiani Bock ${ }^{5}$
}

\begin{abstract}
${ }^{1}$ Doutoranda em Enfermagem do Programa de Pós-Graduação em Enfermagem (PEN) da Universidade Federal de Santa Catarina (UFSC). Enfermeira do Hospital Universitário da UFSC. Santa Catarina, Brasil. E-mail: robertanfr@hotmail.com

${ }^{2}$ Doutora em Enfermagem. Professor Associado do Departamento de Enfermagem e PEN/UFSC. Pesquisadora do CNPq. Santa Catarina, Brasil. E-mail: padilha@nfr.ufsc.br

${ }^{3}$ Doutora em Enfermagem. Professor Adjunto do Departamento de Enfermagem da UFSC. Santa Catarina, Brasil. E-mail: luciamante@nfr.ufsc.br

${ }^{4}$ Doutoranda em Enfermagem do PEN/UFSC. Enfermeira do Instituto de Psiquiatria do Estado de Santa Catarina. Santa Catarina, Brasil. E-mail: elianicostabernardes@hotmail.com

${ }^{5}$ Doutoranda em Enfermagem do PEN/UFSC. Docente do Curso de Enfermagem do Centro Universitário Metodista do Sul. Santa Catarina, Brasil. E-mail: ffabibock@hotmail.com
\end{abstract}

\begin{abstract}
RESUMO: É um estudo descritivo qualitativo com perspectiva histórica com o objetivo de refletir sobre os modos pelos quais Florence Nightingale é representada na produção científica de Enfermagem no período de 1950 a 2008. A fonte de pesquisa foi a base de dados PubMed e foram selecionados para análise 79 resumos destas publicações. Após análise chegou-se as categorias - A história de Florence: o olhar do autor; Saberes e práticas instituídas por Florence Nightingale: das Irmãs de Caridade à Guerra da Criméia; A educação e as pontes para a enfermagem profissional; e Florence Nightingale: feminista, reacionária e administradora? Destaca-se o seu papel como administradora, educadora, estatística, e sua atuação feminista contraditória. Conclui-se que a vida de Nightingale e seu papel enquanto criadora da enfermagem moderna no mundo, é reforçado como algo positivo, uma mulher que dedicou a sua vida para o cuidado do outro e para a profissionalização da enfermagem.
\end{abstract}

DESCRITORES: História da enfermagem. Educação. Biografia.

\section{FLORENCE NIGHTINGALE'S LEGACY: A TRAVEL IN TIME}

\begin{abstract}
The objective of this descriptive, qualitative, historical study is to reflect about the modes in which Florence Nightingale is represented in nursing scientific production from 1950 until 2008. The source of this study was the PubMed database, with 79 studies analyzed through the abstracts of their publications. After analysis, the following categories arose - Florence's history, the author's view, knowledge and practices established by Florence Nightingale: from The Charity Sisters to the Crimean War; Education and the bridges to professional nursing; and Florence Nightingale, feminist, reactionary, and administrator? Her role as an administrator, educator, statistician, and her contradictory feminism is highlighted. It is concluded that Florence Nightingale's life and her role as a modern nursing creator in the world is reinforced as something positive - a woman that dedicated her life to caring for others and to the professionalization of nursing.
\end{abstract}

DESCRIPTORS: History of nursing. Education. Biography.

\section{EL LEGADO DE FLORENCE NIGHTINGALE: UN VIAJE EN EL TIEMPO}

RESUMEN: Es un estudio histórico, descriptivo, de carácter cualitativo, con el objetivo de reflexionar sobre las maneras como Florence Nightingale es representada en la producción científica de Enfermería en el período de 1950 a 2008. Se analizaron 79 estudios de la base de datos PubMed que contenían resúmenes de estas publicaciones. Después del análisis surgieron las siguientes categorías - La historia de Florence: la mirada del autor; Saberes y prácticas establecidas por Florence Nightingale: de las hermanas de la Caridad a la Guerra de Crimea; La educación y los puentes para la enfermería profesional; y Florence Nightingale: ¿feminista, reaccionaria y administradora? Se destaca su papel como administradora, educadora, estadística, y su acción feminista contradictoria. Se concluye que la vida de Nightingale y su papel como creadora de la enfermería moderna en el mundo es destacado como positivo, una mujer que dedicó su vida al cuidado de los otros y a la profesionalización de la enfermería.

DESCRIPTORES: Historia de la enfermería. Educación. Biografia. 


\section{CONSIDERAÇÕES INICIAIS}

Florence Nightingale é considerada a fundadora da Enfermagem Moderna em todo o mundo, obtendo projeção maior a partir de sua participação como voluntária na Guerra da Criméia, em $1854 .{ }^{1}$ Ao retornar da guerra, esta se tornara uma figura popular nacionalmente; seu nome era sinônimo de doçura, eficiência e heroísmo. O trabalho que realizara durante a guerra teve um impacto muito maior do que simplesmente a ação de reorganizar a enfermagem e salvar vidas. Ela quebrara o preconceito que existia em torno da participação da mulher no Exército e transformara a visão da sociedade em relação à enfermagem e ao estabelecimento de uma ocupação útil para a mulher. ${ }^{2}$

A Enfermagem, para Nightingale, era uma arte que requeria treinamento organizado, prático e científico; a enfermeira deveria ser uma pessoa capacitada a servir à medicina, à cirurgia e à higiene e não a servir aos profissionais dessas áreas. $\mathrm{O}$ grande mérito de Florence Nightingale foi dar voz ao silêncio daqueles que prestavam cuidados de enfermagem, que provavelmente não percebiam a importância dos rituais que seguiam, que já indicavam uma prática profissional organizada. ${ }^{1,3}$ Ao institucionalizar a enfermagem como profissão, ela produziu um significado no silêncio que havia na prática de enfermagem, que até então era envolta em regulamentos e correspondências internas às instituições de cuidado, executadas por aquelas que faziam parte de associações, geralmente religiosas, cujo espírito era servir ao próximo, por amor a Deus. ${ }^{1,4}$

A enfermagem é uma profissão que ao longo do tempo vem desconstruindo e construindo sua história. ${ }^{5}$ A sua relação com a sociedade é permeada pelos conceitos, preconceitos e estereótipos que se estabeleceram na sua trajetória histórica e que influenciam até hoje a compreensão de seu significado enquanto profissão da saúde composta de gente que cuida de gente. ${ }^{6}$ Florence Nigthingale e seus pressupostos, de uma forma ou de outra, sempre estiveram ligados à história da enfermagem enquanto profissão, considerando que apenas a partir da fundação da Escola de Enfermagem no Hospital Saint Thomas, inicia-se o período conhecido como Enfermagem Moderna em todo o mundo. Neste sentido, a história torna-se aberta a aproximações e afastamentos das verdades e seus significados.

Nightingale tornou-se uma personagem de si própria, o que pode ser percebido pelo imenso número de livros e artigos sobre algum dos as- pectos que se relacionam a ela diretamente, sem contar as inúmeras citações sobre seus feitos em outros textos, como teses, dissertações, etc. Florence é um mito e como tal foi incluída entre as 100 mulheres que marcaram a história mundial, o que mostra o alcance de sua influência. ${ }^{7}$ Além disso, na Inglaterra, país no qual viveu e iniciou a sua revolução, sua história é ensinada desde a infância nas escolas, como uma das grandes heroínas inglesas. ${ }^{8}$ No entanto, como podemos evidenciar neste texto, sua história é controversa e se por um lado é vista como um anjo de branco que percorre os leitos dos doentes à noite para velá-los, por outro também é representada como o demônio, especialista em maquiavélicas manipulações das pessoas para manter o seu próprio poder e autoengrandecimento. ${ }^{9-10}$

Diante deste contexto, procurando entender e visualizar o processo de construção e desconstrução da história da enfermagem, este estudo tem por objetivo refletir sobre os modos pelos quais Florence Nightingale é representada na produção científica da Enfermagem no período de 1950 a 2008 veiculada na base de dados PubMed.

\section{METODOLOGIA}

É um estudo descritivo qualitativo de perspectiva histórica e que utiliza a pesquisa documental como método de investigação. A elaboração deste estudo tomou por base especialmente artigos relativos à Florence Nightingale e história da enfermagem no período de 1950 a 2008, constituindo-se no que os historiadores denominam de história do presente. ${ }^{11-12}$ Essa relação de passado e presente se estabelece na busca do conhecimento, de maneira a se questionar o passado numa série de questões que são o "agora". Com estas questões, a concepção de verdade sofre uma mudança, como também a aceitação do que vem a ser o resultado da produção do conhecimento, e do valor deste conhecimento produzido.

Neste sentido, foi realizada uma incursão detalhada pela literatura, junto à base de dados PubMed e, consultado os periódicos nacionais e internacionais, sobre o tema. A partir das referências obtidas na primeira etapa, procedeu-se a busca aos resumos dos estudos identificados. Após a coleta dos dados, toda produção foi catalogada, resumida e a análise dos dados foi feita em duas etapas: na primeira etapa, classificamos todos os trabalhos (377) em relação ao ano de publicação e idioma em que os artigos foram escritos. Para a segunda etapa do estudo verificamos que 298 artigos não 
apresentavam o resumo para análise, restando, portanto, 79 resumos destas publicações e foi sobre este corpus que debruçamos para a análise qualitativa. A partir daí estes foram agrupados por semelhanças, dando lugar às categorias temáticas - A história de Florence: o olhar do autor; Saberes e práticas instituídas por Florence Nightingale: das Irmãs de Caridade à Guerra da Criméia; A educação e as pontes para a enfermagem profissional; e Florence Nightingale: feminista, reacionária e administradora?

O marco inicial da produção encontrada na base de dados PubMed foi o artigo de Bennett BA, intitulado Florence Nightingale as an educator, publicado em maio de 1950 pelo Nursing Mirror and Midwives Journal e o final foi o artigo de Williams, K intitulado Reappraising Florence Nightingale, publicado em dezembro de 2008 pelo British Medical Journal. O período histórico da produção científica encontrada sobre o tema se distribui do seguinte modo: 1950-1960: 11; 1961-1970: 36; 1971-1980: 83; 1981-1990: 99 e 1991 em diante: 148. Quanto aos idiomas em que os artigos foram escritos, a maioria (241) se classifica na língua inglesa; 76 em japonês; oito em alemão; sete em francês; cinco em espanhol e italiano; quatro em português e polonês; e os demais em outros idiomas. A seguir apresentaremos as quatro categorias que foram identificadas a partir da análise dos resumos encontrados, com o intuito de favorecer um amplo olhar ao tema.

\section{RESULTADOS E DISCUSSÃO}

\section{A história de Florence: o olhar do autor}

A vida de Florence tem servido de exemplo para a humanidade, especialmente para a Enfermagem. Sua abnegação e decisão em modificar as condições de saúde da sociedade no final do século XIX, marcaram profundamente a história.

Assim, contar, investigar, comprovar sua idoneidade ou desmistificar sua imagem tem sido objeto de estudo para o qual pesquisadores de enfermagem e de áreas afins se voltam. Sua vida tem sido biografada, narrada e divulgada sob variados aspectos. O maior enfoque dos 35 resumos desta categoria versam sobre a história de vida de $\mathrm{Ni}$ ghtingale. Uma dificuldade para constituir o corpus de análise nos eixos aqui propostos, se relaciona ao fato de que os aspectos de sua vida como mulher, enfermeira, política, epidemiologista, visionária, exemplo para outras mulheres, se entrelaçam no mesmo resumo. Assim, é prudente salientar que a divisão apresentada tem a intenção de fazer um panorama das idéias sobre Nightingale e mantém relação direta com o número de ocorrência nos resumos e não com a totalidade destes. O resultado do estudo destes autores pode ser desmembrado em três eixos: o primeiro trata da vida pessoal e familiar, o segundo e mais extenso, se refere a sua vida profissional e o terceiro, mostra a sua imagem no consciente coletivo como um símbolo para a enfermagem e a humanidade ou como algo a ser desmistificado.

Aspectos relativos à família de Nightingale, que era rica, poderosa e mantinha contato com pessoas investidas de poder governamental, o primeiro eixo de discussão, foi enfocado em quatro resumos. Um deles conta que seus pais, após as núpcias, passaram a viajar pela Europa em turnê com uma comitiva luxuosa, por um período de dois anos. Durante esta viagem, nasceram Florence e sua irmã, as quais receberam o nome das cidades onde ocorreram os nascimentos. A casa onde Nightingale nasceu e viveu durante o primeiro ano de vida, na Vila Columbaia, foi alvo de peregrinação de curiosos, historiadores e profissionais da saúde. Esta foi preservada e transformada, primeiramente em uma escola católica privada e, posteriormente, após a Segunda Guerra Mundial, serviu de hospital. Atualmente existe uma construção ocupando aquela área, porém, ainda é referenciada e visitada como o local de seu nascimento. Curiosamente, as freiras que comandavam a escola, precisaram aprender o idioma inglês para atenderem os visitantes que não conheciam o idioma italiano. O fato de sua família ter poder econômico, social e político foi salientado constantemente e considerado como decisivo para que seus feitos fossem propagados. ${ }^{13}$

Onze resumos se referem à educação esmerada e diferenciada daquela oferecida às mulheres de sua época. Os ensinamentos incluíam filosofia, italiano, latim e grego, mas foi em matemática que Nightingale se destacou quando adulta. Ela demonstrou grande capacidade de raciocínio, usando estes conhecimentos nos cálculos que fez como estatística e epidemiologista. Sua inteligência e cultura, bastante incomuns, principalmente para uma época em que a mulher era educada para a vida doméstica, estão registradas nos resumos pesquisados. Durante 16 anos ela se dedicou a vencer a resistência de sua família à sua decisão em se tornar enfermeira. ${ }^{14}$ Seu trabalho na Guerra da Criméia teve grande repercussão, sendo considerado um marco de divisão na história da 
Enfermagem, porém o conhecimento de outros eventos e habilidades evidenciaram sua personalidade plural, atrelada à imagem contemporânea da enfermagem, aspectos estes explorados em cinco resumos.

O segundo eixo temático desta categoria discorre sobre sua atuação profissional e remete para a imagem que é descrita, mostrando a íntima relação entre o que o sujeito faz e o que ele é. A principal contribuição deixada para a Enfermagem, no entanto, foi sua atuação após o término da guerra. Nesta época, ela poderia ocupar qualquer cargo ou ter se aposentado, mas preferiu usar sua influência, promovendo programas educativos e campanhas, criando também a primeira escola de enfermagem. Existe um vínculo entre seu trabalho, suas pesquisas, anotações e habilidades pessoais com a influência política e econômica de sua família. No entanto, é unânime, a idéia de que era uma mulher visionária, determinada, contestadora e questionadora, bem como de seu pioneirismo, dentre eles o uso da ilustração gráfica de dados para apresentar os resultados de suas pesquisas.

Por outro lado, ela promoveu reformas consideradas surpreendentes nos hospitais militares, que com seus princípios de cura e liderança exerceram influência sobre a criação de novas escolas de enfermagem, formação de enfermeiros e médicos dos hospitais militares. Por estas razões é considerada a criadora de uma nova profissão feminina e da Enfermagem Moderna. Contrapondo a imagem desta mulher, dois resumos afirmam que muitas outras mulheres poderiam ter se dedicado em prol de uma causa, no entanto, preferiram seguir os padrões sociais da época. Outras não receberam o devido destaque e permaneceram à sombra de Nightingale, e ainda, as que são assemelhadas a ela no que se refere ao enaltecimento da imagem feminina como símbolo de uma profissão. Artigos produzidos por profissionais de outras áreas, como a odontologia, ou produzidos por enfermeiros de países fora dos Estados Unidos da América, buscam semelhanças na biografia de Nightingale com outras personagens que se destacaram na história, estabelecendo comparações. Em dois resumos existe a referência de que ela é a mais famosa personagem do sexo feminino, vinculando sua história à da medicina e destacam seu nome como um dos mais conhecidos e venerados no mundo.

O relato biográfico confere uma nova roupagem à dialética entre indivíduo e contexto. O indivíduo como sujeito é observado na intimidade de suas relações de amizade, condição social, pertencimento a grupos filosófico-religiosos, região onde viveu e, tecida nestas relações, a realidade biográfica é construída. ${ }^{15}$ Embora autores pretendam desfazer o mito de Nightingale, é indiscutível sua ligação com a prática científica da Enfermagem. A orientação de diferentes ordens religiosas, a presença de virtudes na educação moral dos enfermeiros, são justificativas para a representação social da enfermagem como profissão abnegada e altruísta. A proximidade entre sua imagem e a figura de uma heroína romântica e figura lendária, símbolo positivo para a Enfermagem, é comentado em 10 resumos.

Um grupo de enfermeiros britânicos tentou derrubar o mito de uma mulher que tem sido muitas vezes tratada como uma espécie de santa ou um símbolo de serviço altruísta, tentando inclusive, mudar o dia do enfermeiro, pois este legado de Nightingale seria a razão para aguda escassez de enfermeiros. Constam, em dois resumos, que a alcunha de "Dama da Lâmpada" é questionável uma vez que a lâmpada da enfermagem não era uma lamparina, mas um candeeiro de óleo, algo para iluminar e não um cerimonial imortalizado por um poema. ${ }^{14} \mathrm{Um}$ artigo se volta especificamente para a importância das homenagens feitas à Nightingale, tais como a inclusão de seu nome no calendário de festas na cidade de Washington, além de orações, leituras, e hinos com seu nome e obra. Este mesmo artigo faz referência à Janela Florence Nightingale, localizada na Catedral de Washington, que mostra cenas de sua vida.

$\mathrm{O}$ relato biográfico de Florence é uma interpretação subjetiva de sua trajetória de vida e sujeita a controvérsias opiniões daqueles que se dedicam ao seu estudo. Entretanto, a despeito deste fato, existe a certeza de que estamos diante de alguém que fez bom uso de sua condição social, econômica e política, para promover mudanças positivas na vida das pessoas.

\section{Saberes e práticas instituídas por Florence Nightingale: das Irmãs de Caridade à Guerra da Criméia}

Os saberes e práticas de enfermagem que contribuíram para que Nightingale seja considerada a fundadora da Enfermagem Moderna em todo o mundo, foram oriundos também, de suas experiências anteriores à guerra da Criméia, em 1854, ou seja, sua educação aristocrática que lhe permitiu ter acesso a vários idiomas, à matemática, religião e filosofia e seus estágios com as Irmãs de Caridade, onde aprendeu os primeiros passos da disciplina na 
enfermagem (regras, horários rígidos, religiosidade e divisão do ensino por classes sociais). ${ }^{1,16}$

Nesta categoria elencamos os textos que tinham como temática principal as normas de conduta e práticas instituídas a partir de Florence Nightingale, assim como as publicações que analisam sua atuação na Guerra da Criméia. Encontramos 18 resumos, sendo que a maioria é específica sobre a Guerra. Os resumos que discorrem sobre a temática analisam a forma como Nightingale se tornou um mito da era Vitoriana, apontando suas contribuições a respeito da medicina militar. Descrevem a prática da enfermagem a partir de sua atuação na Criméia. Um deles inclusive compara os serviços de alimentação propostos por Florence, no atendimento aos soldados doentes e feridos, com as mais modernas recomendações de ingestão dietética. $\mathrm{O}$ trabalho que realizara durante a guerra teve um impacto muito maior do que simplesmente a ação de reorganizar a enfermagem e salvar vidas. Ela quebrara o preconceito que existia em torno da participação da mulher no Exército e transformara a visão da sociedade em relação à enfermagem e ao estabelecimento de uma ocupação útil para a mesma. ${ }^{2}$

Com relação à Guerra, encontramos ainda um artigo que analisa a atuação das enfermeiras russas, que estiveram do outro lado da Guerra da Criméia, enfermeiras voluntárias que também contribuíram para aliviar o sofrimento dos doentes e feridos. Apenas dois artigos analisam historicamente as ligações entre a prática da enfermagem de Florence Nightingale e as Irmãs de Caridade. Esta foi influenciada diretamente pela sua passagem nos locais onde se executava o cuidado de enfermagem leigo e fundamentado nos conceitos religiosos de caridade, amor ao próximo, doação, humildade, e também pelos preceitos de valorização do ambiente adequado para o cuidado, divisão social do trabalho em enfermagem e autoridade sobre o cuidado a ser prestado. ${ }^{17}$

Nesta categoria agrupamos ainda, resumos que abordam as práticas de saúde que foram influenciadas por Nightingale, tais como, a reforma sanitária na Índia, melhores práticas de saúde do povo indígena da Austrália, avanços no controle da infecção e epidemiologia hospitalar, além de lições para a enfermagem moderna. Cabe mencionar que as idéias de Nightingale, acerca da enfermagem como profissão, chocavam-se com a ideologia da era vitoriana, correspondente à prática da enfermagem, que era considerada como uma forma de ocupação manual desempenhada por empregadas domésticas e cujo sentido da palavra se restringia a pouco mais do que a ministração de remédios e aplicação de emplastros. ${ }^{18}$ Segundo ela, deveria significar, porém emprego apropriado de ar puro, luz, calor, limpeza, quietude e a adequada escolha e administração da dieta - tudo com o mínimo gasto da força vital do paciente. ${ }^{18}$

Destacamos ainda dois estudos que relatam alguns comentários hostis sobre o Anjo de Scutari (da Criméia), apontando que algumas vezes, Florence foi depreciada e ignorada pela literatura. Os resumos revelam que grande parte da reputação de Florence baseia-se em mitos criados pela imprensa popular, além disso, uma de suas biografias foi encomendada pela sua família após a sua morte, portanto, dificilmente pode ser considerada imparcial. E um segundo livro foi escrito por Woodham-Smith, em um tempo que se necessitava desesperadamente de figuras heróicas. ${ }^{19}$

\section{A educação e as pontes para a enfermagem profissional}

Florence Nightingale teve importante participação na construção do ensino de enfermagem, através de seus saberes e práticas relacionadas à profissão. Sua contribuição é inegável frente a seu poder de observação. Além disso, defendia suas posições com base em prévia investigação. Nesta categoria, elencamos os resumos que tinham como temática principal a educação, instituída a partir de Florence Nightingale, assim como as publicações que analisam sua influência no ensino, nas escolas, nos currículos e nas teorias de enfermagem. Encontramos 12 resumos, sendo que a maioria aborda as questões relacionadas ao desenvolvimento curricular da enfermagem a partir de Florence. Um dos resumos evidencia a importância dos conceitos holísticos em enfermagem e o desenvolvimento curricular proposto pela American Holistic Certification Corporation e da American Holistic Nurses, baseado na atenção holística às necessidades dos pacientes. São discutidas as dificuldades e barreiras enfrentadas para a inclusão do holismo na educação em enfermagem.

Ressaltamos que em dois resumos a enfermagem é percebida como uma disciplina em evolução, que exige domínio e produção do conhecimento. Existe atualmente, um maior interesse ao ensino da enfermagem, estando evidente pelo crescimento das pesquisas na área e pelo número de publicações concentradas na teoria do conhecimento em enfermagem. Estes esforços têm contri- 
buído para o avanço da disciplina, e desafiam as enfermeiras a articular os fundamentos teóricos da sua própria prática. Nightingale defendia o ensino da enfermagem ligado à instituição hospitalar, e considerava o ideal da enfermagem uma vocação, que requeria dedicação exclusiva e árdua preparação. Segundo a história, Ethel Bedford Fenwick, contemporânea de Nightingale, juntamente com a Associação Britânica de Enfermeiras (British Nurses Association, atualmente Royal College of Nursing), defendia o ensino de enfermagem na universidade, e travou lutas para conquistar um registro nacional de enfermeiras e a criação de um órgão legalmente reconhecido, constituído por enfermeiras, que tomasse nas mãos os destinos da profissão. Apesar da oposição de Florence e seus aliados ligados aos hospitais, Fenwick conseguiu com o apoio da Associação Britânica de Enfermeiras fundar o Conselho Internacional de Enfermeiras, em 1899. ${ }^{2}$

Em um dos resumos analisados, que examinou a história e sociologia da educação em enfermagem na Inglaterra entre 1860 e 1948, busca aproximar a enfermagem dos serviços de saúde e das ciências sociais. Defende uma forte coligação da enfermagem com o seu antigo aliado do século XIX, a ciência social. Além disso, traz em suas discussões a necessidade da enfermagem em unir forças com os sociólogos e economistas, para sua visibilidade e transformação política. Nightingale defendia a idéia de que as enfermeiras não podiam estar afastadas da atividade política, sob pena de não se conseguirem as reformas necessárias para a prestação de bons cuidados à saúde. O caminho político seria um atalho para a conquista de maior espaço da enfermagem e para que fosse mais valorizada pela sociedade. ${ }^{2}$

Possuidora de incomum conhecimento para a época, Florence pode ser considerada a primeira pesquisadora de enfermagem no mundo. Crenças espiritualistas nortearam sua trajetória de vida. A constante preocupação e o envolvimento com o sofrimento de seus semelhantes seriam, segundo registro em seu diário, decorrentes dos chamados de Deus. ${ }^{20}$

No instituto de Diaconisas de Kaiserswerth na Alemanha, aprendeu os primeiros passos da disciplina em enfermagem. Estes ensinamentos eram semelhantes aos preconizados pelas irmãs de Caridade de São Vicente de Paulo. Preocupavam-se mais com o caráter de suas alunas do que em ministra-lhes conhecimentos específicos de enfermagem. ${ }^{17}$ Por seu senso de observação,
Florence registrava sempre suas impressões em apontamentos, e utilizou seus conhecimentos de matemática e estatística, que resultaram em várias publicações. Mais tarde deu origem às prescrições médicas por escrito e, também, exigia que suas enfermeiras acompanhassem os médicos em suas visitas aos pacientes, para prevenirem erros, instruções esquecidas ou ignoradas, e diretivas mal compreendidas, pois para a melhoria do estado de saúde do país, o ensino de enfermagem era uma grande responsabilidade das enfermeiras. ${ }^{21}$ Ela tornou-se pioneira na utilização de gráficos para apresentar dados em uma forma clara para que todos pudessem compreender. Criou um diagrama e o utilizou para representar graficamente as taxas de mortalidade durante a guerra da Criméia. ${ }^{2}$

Dois resumos apresentam apontamentos sobre a influência de Nightingale nos métodos estatísticos, incluindo estatísticas morais e ciências sociais. Em um dos textos estudados verificamos a utilização dos ensinamentos históricos desta, para a construção de uma ferramenta visual de ilustração gráfica de dados em cirurgias de reconstrução ligamentar de joelho. O instrumento facilitaria o acesso de dados do paciente, pela equipe multidisciplinar. ${ }^{22}$ Relembrando os primórdios da Enfermagem moderna, é em Florence que se encontra a primeira tentativa de distinguir os saberes da Medicina dos da Enfermagem. Por essa razão, hoje Nightingale é considerada a primeira teórica da Enfermagem. No final da década de 60 do século XX, outras teóricas, percebendo que o saber expresso pelos princípios científicos era dependente e não possuía natureza específica, incumbiram-se de construir um modelo de conhecimentos próprio para a Enfermagem na tentativa de conferir-lhe o status de ciência. ${ }^{23}$

Os textos, que discorrem sobre as teorias de enfermagem instituídas a partir de Florence relatam que estas são definidas como a árvore da vida, e que ajuda a organizar a prática das enfermeiras, associando a teoria à prática. Percebemos que Florence consolidou de certa forma os fundamentos que serviram de base ao ensino de enfermagem, mas que esta temática merece constantes reflexões acerca da profissão e sua cientificidade.

\section{Florence Nightingale: feminista, reacionária e administradora?}

Esta categoria tem por finalidade apresentar os modos pelos quais as questões de gênero e ação política permeiam os estudos relativos a Florence 
Nightingale. Neste sentido foram detectados 14 resumos que se debruçam sobre esta questão e que passaremos a discutir.

Para introduzir o assunto tomamos por empréstimo as próprias idéias de Nightingale para definir a profissão que estava criando e que implicava na conduta feminina da época. Nas - Notas sobre Enfermagem, esta se refere aos aspectos que a enfermagem deve ser e facilmente podemos correlacionar com o mesmo espera-se da mulher. Então vejamos: "Toda enfermeira deve ser uma pessoa com quem se pode contar, isto é, capaz de ser uma enfermeira 'de confiança'. [...] Deve ser estritamente sóbria, honesta e, mais do que isso, ser uma mulher religiosa e devotada. Deve ser uma observadora segura, direta, rápida e ser uma mulher de sentimentos delicados e modestos" . 18:164

Contrapondo-se a esta idéia, encontramos três resumos que refletem sobre a profissão de enfermagem através da história e de certo modo culpabilizam Nightingale por tê-la transformado em profissão feminina. A argumentação dos autores é de que a enfermagem sempre foi exercida por homens e mulheres na mesma proporção, tanto para cuidar de guerreiros feridos, gestantes, crianças e idosos, o que não pode ser negado pela história da enfermagem. Homens e mulheres buscam a enfermagem por motivos diferentes, porém sociólogas feministas expressam preocupação no número desproporcional de homens em posições gerenciais de enfermagem e isto pode ter conseqüências negativas para a profissão.

Para atender as questões contidas na reflexão sobre estas questões entendemos que é necessário definirmos a concepção de gênero adotada neste estudo. Neste sentido, entendendo gênero como uma construção histórica, teríamos que supor que o conceito é plural, ou seja, haveria conceitos de feminino e masculino, social e historicamente diversos. A idéia de pluralidade implicaria em admitir não apenas que sociedades diferentes teriam concepções diferentes de homem e mulher, mas também que no interior de uma sociedade tais concepções seriam diversificadas, conforme a classe, a religião, a raça a idade, etc. ${ }^{24-25}$ A construção dos papéis sexuais direciona, inclusive a escolha profissional, estabelecendo que a mulher, atendendo ao condicionamento recebido desde a infância, escolhe uma carreira condizente com a sua condição "feminina", como professora primária, secretária, enfermeira, etc., que são consideradas, por muitos, como pouco qualificada e competitiva no mercado de trabalho. ${ }^{25-26}$
Outro aspecto relativo às questões de gênero, assim como a sua participação política, são abordados em cinco resumos, que apresentam contradições entre os autores que discutem a atuação de Nightingale. Uma destas está entre aqueles que a consideram uma feminista, especialmente pela resistência a sua família quando ela decidiu tornar-se uma enfermeira, e a rejeição por Nightingale das expectativas sociais do que se esperava de uma mulher na Era Vitoriana. ${ }^{27-29}$ Outros autores discordam desta idéia ao refletirem sobre algumas atitudes de Nightingale contrárias a uma postura feminista, tais como, quando esta se opôs a entrada de mulheres na profissão médica, e também quando se negou a participar do movimento - o novo sufrágio para as mulheres da sociedade - (Women's Suffrage Society), pelo voto feminino e ampliação dos direitos das mulheres na sociedade inglesa. ${ }^{27}$

Embora reconhecida como a fundadora da enfermagem moderna, Florence foi criticada pela sua aparente falta de apoio nas questões da mulher, porém desenvolveu um complexo conjunto de crenças que apoiaram as mulheres como indivíduos e não a partir de uma perspectiva de gênero tal qual preconizada pelas autoras feministas. Ela fez, na realidade, reforçar o conceito de sufrágio da mulher, mas não lhe deu prioridade. $\mathrm{Na}$ era Vitoriana as mulheres sofreram de falta de estatuto jurídico, a educação, a independência financeira, e desejavam o apoio da família ou da igreja como instituições sociais. ${ }^{30}$ Um dos autores analisa a ligação entre Nightingale e sua contemporânea, Barbara Leigh-Smith Bodichon. Esta última foi à fundadora do The Women's English Journal que proporcionou uma plataforma pública para os principais textos feministas do período. Criou o Centro Administrativo da Society for Promoting the Employment of Women. As mulheres que atuavam neste local eram chamadas de Langham Place Group. Um fato inexplorado foi o de que Leigh-Smith e Nightingale eram primasirmãs. O autor explora os pontos de vista de ambas, Nightingale e Leigh-Smith para obter uma compreensão mais clara das relações existentes entre a enfermagem e feminismo. ${ }^{27}$

Para Florence, a Enfermagem era compreendida, tanto como vocação quanto como profissão, e os dois aspectos deviam estar unidos, sendo que qualquer mulher poderia vir a ser uma boa enfermeira. O sentimento de religiosidade marcou parcialmente o ideário da enfermagem, principalmente quando se alia a este, àquelas qualidades 
desejadas, tanto para a religiosa quanto para a enfermeira, como obediência, respeito à hierarquia e humildade. ${ }^{31-34}$

Traçando uma rápida retrospectiva histórica, evidenciamos que ao longo dos séculos, desde a idade antiga até a atualidade, tanto o gênero masculino como o feminino, sempre dividiram espaço no cuidar do corpo do outro. Em alguns momentos, a história privilegiou os homens, principalmente na idade média, quando as mulheres eram perseguidas como bruxas, à exceção daquelas que abandonavam suas famílias e riquezas (diaconisas, abadessas, beguinas), para se dedicarem aos pobres e doentes. O gênero masculino era representado por físicos e cirurgiões-barbeiros, que se responsabilizavam pela cura dos males físicos. $\mathrm{Na}$ idade média, posteriormente, proliferaram as ordens religiosas de homens e mulheres, que cuidavam dos corpos e almas dos pobres e doentes, sendo que alguns são lembrados até hoje nas figuras de santos, como Santo Agostinho e São Vicente de Paulo. As mulheres, por sua vez, em ordens religiosas leigas, como as Irmãs de Caridade, estabeleceram rituais de cuidados de enfermagem nos hospitais e domicílios, imprimindo suas marcas à prática de enfermagem. . $^{1-2}$

Com a emergência do capitalismo, a partir do final do século XVIII e meados do século XIX, dois movimentos foram fundamentais para implementar novas mudanças nas relações sociais, políticas e estruturais, levando ao processo de acumulação capitalista: a revolução industrial iniciada na Inglaterra e o movimento social que culminaram na Revolução Francesa de 1789. Com o advento da maquinaria, houve um aproveitamento da mão-de-obra feminina e infantil, mais baratas, mantendo o mesmo ritmo de produção. Essa incorporação tornou-se necessária para o operariado, como forma de garantir a sobrevivência do núcleo familiar. Contudo, sob a dominação masculina, a mulher era ainda mais explorada, recebendo, em média, 50\% a menos do que o homem, pelo mesmo trabalho. Blay reforça esta análise sobre o trabalho industrial e doméstico, dizendo que "na sociedade burguesa o duplo papel econômico da mulher aparece ao nível da consciência social através de uma ideologia que justifica e glorifica o trabalho doméstico e que endossa o trabalho industrial" . $35: 8$

Voltando ao tema em questão, salientamos que o nome de Florence Nightingale cruzou os mares e fez com que esta fosse considerada o modelo de enfermeira a ser seguido para a criação dos primeiros cursos de enfermagem nos países que adotaram o sistema Nightingaleano. As alunas do curso de enfermagem eram consideradas enfermeiras padrão.

\section{CONSIDERAÇÕES FINAIS}

Em termos de biografias na enfermagem e controversas discussões, Florence desponta com inúmeros artigos e livros escritos por enfermeiras e historiadores interessados em sua história, papel social, político, educativo, administrativo, feminista e histórico, retratando a sua vida desde o seu nascimento até a morte. Estes resumos na sua grande maioria são escritos em inglês e restritos, portanto, aos leitores que dominam este idioma, a exceção do Livro Notas de Enfermagem, que foi traduzido para outros idiomas, dentre eles, o português.

A vida de Nightingale e seu papel enquanto criadora da Enfermagem Moderna no mundo é destacado como algo positivo, como uma mulher que dedicou a sua vida para o cuidado do outro e para a profissionalização da enfermagem, representada pela dama da lâmpada, incansável missionária. Independente das críticas e elogios, o nome de Florence Nightingale e os componentes como honestidade, sobriedade, religiosidade e devoção, a habilidade de observação minuciosa e a delicadeza, como atributos de uma enfermeira confiável, fizeram com que esta fosse considerada um modelo de enfermeira em todo mundo.

\section{REFERENNCIAS}

1. Padilha MICS. A mística do silêncio - a enfermagem na Santa Casa de Misericórdia do Rio de Janeiro no século XIX. Pelotas (RS): UFPel; 1998.

2. Oguisso T. Florence Nightingale. In: Oguisso $\mathrm{T}$, organizador. Trajetória Histórica e Legal da Enfermagem. São Paulo (SP): Manole; 2005. p.59-97.

3. Kruse MHL. Os poderes dos corpos frios - das coisas que se ensinam às enfermeiras. [tese]. Porto Alegre (RS): Universidade Federal do Rio Grande do Sul. Programa de Pós-Graduação em Educação; 2003.

4. Barreira IA. Contribuição da história da enfermagem brasileira para o desenvolvimento da profissão. Esc Anna Nery Rev Enferm. 1999 Abr; 3(1):125-41.

5. Padilha MICS, Borenstein MS. O método de pesquisa histórica na Enfermagem. Texto Contexto Enferm. 2005 Out-Dez; 14(4):575-84.

6. Padilha MICS, Borenstein MS. O panorama da história da enfermagem na região sul do Brasil. Esc Anna Nery Rev Enferm. 2000 Dez; 4(3):369-75.

7. Rolka GM. 100 Women who shaped world history. San Francisco (US): Bluewood Books; 1994. 
8. Adler DA. A Picture Book of Florence Nightingale (Picture Book Biography). United Kingdon (UK): Paperback editions; 1997.

9. D'Antonio P. Florence Nightingale by herself. Bull Hist Med. 1995 Summer; 69(2):278-87.

10. Auerbach N. Women and demon: the life of a Victorian Myth. Cambridge (US): Harvard University Press; 1982.

11. Le Goff J. A História Nova. São Paulo (SP): Martins Fontes; 1990.

12. Certeau M. A escrita da história. Rio de Janeiro (RJ): Forense universitária; 1982.

13. Baly ME. Florence Nightingale and the nursing legacy. Philadelphia (US): BainBridgeBooks; 1998.

14. Donahue MP. Historia de la enfermeria. Barcelona (ES): Doyma, 1993.

15. Foucault M. Microfísica do Poder. Rio de Janeiro (RJ): Graal, 1986.

16. Strachey L. Eminent Victorians. London (UK): Books, 1986.

17. Padilha MICS, Mancia JR. Florence Nightingale e as irmãs de caridade: revisitando a história. Rev Bras Enferm. 2005 Nov-Dez; 58(6):723-6.

18. Nightingale F. Notes on nursing: what is and what is not. New York (US): Dover publications; 1969.

19. Williams K. Reappraising Florence Nightingale. BMJ. 2008 Dec; 16(337):a2889.

20. Gomes VLO, Backes VMS, Padilha MICS, VAZ MRC. Evolution of scientific knowledge in the nursing field: the popular care of construction of theories. Invest Educ Enferm. 2007 Jul-Dec; 25(2):108-15.

21. Palmer IS. From whence we came. In: Chaska NL. The nursing profession: A time to speak. New York (US): McGraw Hill; 1983.

22. Meyers PD, Mcnicholas MJ. Improved data illustration in complex multi-ligament knee reconstruction surgery: using the historical principles of Florence Nightingale and Jonh Venn. Acta Ortoped. 2008 Apr; 79(2):2444-8.
23. Meyer DE. A formação da enfermeira na perspectiva do gênero: uma abordagem sócio-histórica. In: Lopes JM, Meyer DE, Waldow VR. Maneiras de cuidar, maneiras de ensinar: a enfermagem entre a escola e a prática profissional. Porto Alegre (RS): Artes Médicas, 1996. p.63-78.

24. Louro GL Gênero, sexualidade e educação: uma perspectiva pós-estruturalista. Petrópolis (RJ): Vozes, 1997.

25. Chodorow NJ. Gender as a Personal and Cultural Construction. Signs. 1995 Spring; 20(3):516.

26. Scott J. Genre: une catégorie utile d'analyse historique. Cahiers du grif. 1988; (37-38):125-53.

27. Hektor LM. Florence nightingale and the women's movement: friend or foe?. Nurs Inquir. 1994 Nov; 1(1):38-45.

28. Holliday ME, Parker DL. Florence Nightingale, feminism and nursing. J Adv Nurs. 1997 Sep, 26(3):483-8.

29. Malpas P. Florence Nightingale: appreciating our legacy, envisioning our future. Gastroenterol Nurs. 2006 Nov-Dec; 29(6):447-52.

30. Selanders LC. Florence Nightingale. The evolution and social impact of feminist values in nursing. J Holist Nurs. 1998 Jun, 16(2):227-43

31. Nelson S. Say little, do much'. Nineteenth-century nursing and hospital foundation by religious women in the New World. Pensilvânia (US): University of Pennsylvania Press; 2001.

32. Baldwin DO. Discipline, Obedience, and Female Support Groups: Mona Wilson at the Johns Hopkins Hospital School of Nursing, 1915-1918. Bull Hist Med. 1995 Winter; 69(4):599-619.

33. Clarke L. So what exactly is a nurse?. J Psychiatr Ment Health Nurs. 2006 Aug; 13(4):388-94

34. MacIntosh J. Reworking Professional Nursing Identity. West J Nurs Res. 2003 Oct; 25(6):725-41.

35. Blay EA. Urbanização em região sub-desenvolvida. São Paulo (SP): Ática; 1975.

E-mail: robertanfr@hotmail.com 